\title{
Association between smell and taste dysfunction and obesity and metabolic syndrome in older adults*
}

\author{
Sebastian S. Dobrow', Jamiluddin J. Qazi', Spencer C. Payne ${ }^{1,2}$, \\ Jose L. Mattos ${ }^{1,2}$ \\ University of Virginia School of Medicine, Charlottesville, VA, USA \\ 2Department of Otolaryngology - Head and Neck Surgery, University of Virginia, Charlottesville, VA, USA
}

Rhinology Online, Vol 4: 210 - 217, 2021

http://doi.org/10.4193/RHINOL/21.023

*Received for publication:

May 18, 2021

Accepted: October 17, 2021

Published: November 20, 202

\begin{abstract}
Background: Obesity and metabolic syndrome (MS) are prevalent and associated with negative health outcomes in the elderly. There is a need to identify risk factors for these diseases in this population.

Methodology: The 2013-14 National Health and Nutrition Examination Survey was used in this study. Adults $\geq 60$ were categorized into normosmia, hyposmia, anosmia, and combined anosmia + hyposmia using the Pocket Sniff Test. Taste was evaluated using quinine and $\mathrm{NaCl}$ solutions. Multivariate logistic regression models were used to characterize associations between smell and taste status and obesity and MS.
\end{abstract}

Results: In univariate obesity analysis, normosmia, combined anosmia + hyposmia, and $0.32 \mathrm{M} \mathrm{NaCl}$ taste dysfunction were significant. $0.32 \mathrm{M} \mathrm{NaCl}$ taste dysfunction remained significant in multivariate analysis. MS was significantly associated with only tongue tip quinine dysfunction in univariate and multivariate analyses.

Conclusions: Salty taste dysfunction was found to be negatively associated with obesity while bitter taste dysfunction was found to be positively associated with MS.

Key words: Smell dysfunction, Taste dysfunction, Obesity, Metabolic syndrome, NHANES

\section{Introduction}

Smell and taste dysfunction can have significant effects on quality of life and mortality, especially in older adults ${ }^{(1-3)}$. In the United States, the prevalence of smell and taste impairment may be as high as $13 \%$ and $17 \%$, respectively ${ }^{(4-6)}$. It has also been shown that this prevalence increases with age ${ }^{(6-8)}$. Yet, despite the high prevalence and adverse consequences of smell and taste dysfunction, literature characterizing these conditions remains relatively undeveloped.

It is known that food choice and food intake are influenced by smell and taste ${ }^{(9)}$. As such, it is unsurprising that associations have been found between metabolic diseases, such as type 2 diabetes mellitus, and impaired smell and taste ${ }^{(10-13)}$. The pathophysiology underlying these associations is complex and an active area of study ${ }^{(10,14)}$. We investigate both obesity and metabolic syndrome in this study. While these two conditions are likely pathophysiologically related, they are independent diseases and therefore could have different risk factors ${ }^{(10-15,16)}$. Obesity, defined as a body mass index (BMI) greater than or equal to $30 \mathrm{~kg} / \mathrm{m}^{2}$, has reached an unprecedented prevalence in the United States ${ }^{(15,17)}$. It is estimated that by 2030 , up to $86 \%$ of adults in the United States will be obese ${ }^{(15)}$. Obesity is associated with a decrease in life expectancy of up to almost 20 years (15). For each $5 \mathrm{~kg} / \mathrm{m}^{2}$ above a BMI $25 \mathrm{~kg} / \mathrm{m}^{2}$, there is an increase in mortality of $30 \%$ on average, mostly owing to cardiovascular causes ${ }^{(15)}$. The etiology of obesity is likely multifactorial, but 
overconsumption of nutrient-poor foods is an established risk factor $^{(14,15,18)}$.

In the United States, the number of adults aged 65 years or older is predicted to nearly double by the year $2050^{(18)}$. Additionally, the literature estimates that currently about $40 \%$ of adults over 60 years of age in the United States are obese and this will continue to increase ${ }^{(19)}$. This suggests a substantial portion of the American population will be elderly and obese in the future. In combination with age-related comorbidities, obesity in this population can substantially and negatively impact the health and quality of life ${ }^{(20,21)}$. In fact, the obesity-related decline in functional status increases risk for falls and other adverse events, as well as increasing the risk of institutionalization ${ }^{(20,21)}$. Therefore, it is important to be able to identify risk factors for obesity in this unique population.

Since smell and taste influences food preferences, there would seem to be a connection between disorders of smell or taste and obesity. However, despite this intuitive link, the literature regarding the association between smell and taste dysfunction and obesity is sparse and riddled with contradictory results. Some studies have found increased BMI to be associated with olfactory dysfunction; others have found no connection $(4,10,22,23)$. With regard to taste, increasing BMI has been associated with decreased taste sensitivity in certain studies, while others have linked obesity to increasing sensitivity towards sweet, salty, or fatty tastes ${ }^{(22,23,26,27)}$. These discrepancies are likely due to methodological inconsistencies between studies. It is also worth noting that very few studies have examined the link between obesity and smell dysfunction (SD) or taste dysfunction (TD) in the elderly, so it is difficult to apply many existing conclusions in the literature to this population.

Metabolic syndrome (MS) is another disease influenced by nutritional choices; the pathology consists of insulin resistance, hypertension, dyslipidemia, and central obesity ${ }^{(15,16)}$. MS is associated with a 2-fold increase in the risk of coronary heart and cerebrovascular disease, and a 1.5-fold increase in all-cause mortality ${ }^{(15)}$. An estimated $33 \%$ of adults in the United States are estimated to meet the criteria of MS ${ }^{(15,28,29)}$. This prevalence is estimated to increase with age ${ }^{(30)}$.

In fact, the estimated prevalence of MS in adults over 55 years is $37 \%$, higher than that in the general population ${ }^{(31)}$. In older adults, MS has been associated with many negative health outcomes, including higher risk of cardiovascular morbidity and mortality, declines in mobility, and poorer quality of life ${ }^{(32-36)}$. Early identification of older adults at risk for MS could facilitate targeted interventions to mitigate further illness and functional decline.

Despite the high prevalence of this disease, the literature describing MS's association with smell and taste dysfunction is very sparse. One study in 2016 showed an association between smell dysfunction and metabolic syndrome ${ }^{(16)}$. Another showed worse smell and taste dysfunction was associated with higher total serum cholesterol levels, a component of MS ${ }^{(30)}$. However, to the best of our knowledge, no study has used a nationally representative, cross-sectional database to examine the association between MS and objective smell and taste dysfunction in older adults.

In this investigation, our objective was to evaluate for independent associations between SD and TD and obesity as well as MS using a nationally representative sample of older adults in the United States.

\section{Materials and methods}

The National Center for Health Statistics (NCHS), a part of the Centers for Disease Control and Prevention (CDC), completes the National Health and Nutrition Examination Survey (NHANES) annually. NHANES samples about 5,000 non-institutionalized civilians, located in 15 different counties each year and applies a complex probability sampling algorithm to produce a nationally representative cohort of individuals across the United States ${ }^{(37)}$. Interviews are conducted in participants homes while examinations and measurements occur in equipped mobile centers, which travel to locations throughout the country. A physician, medical and health technicians, and dietary and health interviewers comprise the study team. Participation is voluntary and recruitment is carried out by letter from the NCHS director as well as coverage by local media. Participation is voluntary, transportation is provided to mobile centers if required and compensation as well as a report of medical findings is provided to each participant ${ }^{(38)}$.

The survey collects comprehensive health information from these participants, including smell and taste data using subjective (self-reported) as well as quantitative testing methods (39). This data is entirely de-identified and available for public use ${ }^{(37)}$. In this investigation, the 2013-2014 NHANES data were used to examine the associations between obesity or MS and quantitative SD and TD in adults 60 years of age or older.

NHANES uses the Pocket Smell Test (PST) to evaluate SD. The PST is an 8-question odor identification test where the participant must choose the correct response from a list of 4 smell description options. The odors include strawberry, chocolate, onion, grape, natural gas, smoke, leather, soap (Pocket Smell TestsTM, Sensonics International, Haddon Heights, NJ, USA). Each correct answer is recorded, generating a score between 0 and 8 . With respect to evaluating SD, the PST has shown high testretest reliability over 2 -week intervals ${ }^{(7,8,40)}$. Cut-off values were chosen for the PST from the literature as sensitive and specific ways to evaluate for SD ${ }^{(5,8)}$. Participants were labeled as having SD if they had a score of $\leq 5$ on the PST. This was divided into hyposmia (score of 4-5) and anosmia (score $\leq 3$ ). Normosmia was a score of $>5$ on the PST.

NHANES uses a 5-item taste identification test to evaluate for 
Table 1. Unweighted Cohort Characteristics, stratified by smell and taste dysfunction.

\begin{tabular}{|c|c|c|c|c|c|c|c|c|}
\hline \multirow[b]{2}{*}{ Characteristics } & \multicolumn{3}{|c|}{ Smell Assessment } & \multicolumn{5}{|c|}{ Taste Assessment } \\
\hline & Normosmia & $\begin{array}{l}\text { Hyposmia }+ \\
\text { Anosmia }\end{array}$ & Anosmia & $\begin{array}{l}\text { *Quinine } \\
\text { Dysfunc- } \\
\text { tion }\end{array}$ & $\begin{array}{l}\text { *NaCl 1M } \\
\text { Dysfunc- } \\
\text { tion }\end{array}$ & $\begin{array}{c}\text { *NaCl } \\
0.32 \mathrm{M} \text { Dys- } \\
\text { function }\end{array}$ & $\begin{array}{l}\text { *Quinine } \\
\text { Tongue Tip } \\
\text { Dysfunc- } \\
\text { tion }\end{array}$ & $\begin{array}{l}\text { *NaCl } \\
\text { Tongue Tip } \\
\text { Dysfunc- } \\
\text { tion }\end{array}$ \\
\hline $\mathrm{N}(\%$ of total $n$ ) & 81.20 & 18.80 & 4.10 & 14.60 & 3.20 & 10.80 & 62.60 & 17.60 \\
\hline Age, mean, years & 68.4 & 71.9 & 73.7 & 68.8 & 70 & 68.9 & 69.1 & 69.5 \\
\hline \multicolumn{9}{|l|}{ Sex (\% of subgroup) } \\
\hline Female & 55.40 & 41.40 & 20.00 & 50.70 & 60.60 & 55.60 & 51.60 & 47.80 \\
\hline \multicolumn{9}{|l|}{$\begin{array}{l}\text { Race/ethnicity (\% of sub- } \\
\text { group) }\end{array}$} \\
\hline Mexican American & 3.50 & 3.80 & 1.30 & 4.20 & 4.40 & 3.70 & 4.50 & 3.80 \\
\hline Other Hispanic & 1.90 & 4.10 & 1.10 & 3.20 & 3.80 & 3.30 & 2.70 & 2.20 \\
\hline Non Hispanic White & 66.20 & 74.40 & 79.80 & 80.40 & 81.60 & 80.60 & 79.70 & 79.80 \\
\hline Non Hispanic Black & 6.20 & 11.10 & 11.60 & 8.90 & 7.20 & 7.20 & 8.40 & 9.00 \\
\hline Non Hispanic Asian & 2.30 & 5.50 & 5.90 & 1.60 & 2.90 & 3.60 & 3.30 & 4.10 \\
\hline Other / Multiracial & 1.10 & 1.20 & 0 & 1.70 & 40 & 1.50 & 1.40 & 1.10 \\
\hline \multicolumn{9}{|l|}{ Education (\% of subgroup) } \\
\hline Less than high school & 13.10 & 18.80 & 10.60 & 18.70 & 14.80 & 11.60 & 15.10 & 10.90 \\
\hline High school graduate & 54.00 & 59 & 55.70 & 49.80 & 38.40 & 49.70 & 52.40 & 68.10 \\
\hline College graduate & 33.00 & 22.20 & 33.50 & 31.40 & 46.60 & 38.80 & 32.50 & 21.00 \\
\hline \multicolumn{9}{|l|}{ Income (\% of subgroup) } \\
\hline$<\$ 20,000$ & 14.50 & 17.00 & 17.50 & 15.20 & 24.70 & 14.30 & 15.20 & 16.30 \\
\hline$\$ 20,000-\$ 44,999$ & 26.80 & 33.50 & 26.60 & 33.90 & 18.80 & 30.30 & 26.70 & 24.70 \\
\hline$\$ 45,000-\$ 74,999$ & 21.90 & 17.80 & 18.20 & 12.90 & 21.60 & 17.10 & 21.50 & 24.00 \\
\hline$>\$ 75,000$ & 31.30 & 24.40 & 35.20 & 32.30 & 25.30 & 32.00 & 30.80 & 27.80 \\
\hline unknown & 5.50 & 7.30 & 27.10 & 5.50 & 9.70 & 6.30 & 5.70 & 7.10 \\
\hline Hypertension (\% of subgroup) & 59.60 & 67.70 & 49.80 & 66.30 & 62.50 & 60.20 & 61.90 & 60.00 \\
\hline Cardiovascular disease (\%) & 17.90 & 81.70 & 19.20 & 21.00 & 29.70 & 17.00 & 18.50 & 21.70 \\
\hline Diabetes (\% of subgroup) & 18.90 & 20.90 & 14.00 & 19.30 & 24.70 & 10.60 & 18.40 & 23.20 \\
\hline Stroke (\% of subgroup) & 5.80 & 11.10 & 10.60 & 7.10 & 11.90 & 4.60 & 8.20 & 5.50 \\
\hline \multicolumn{9}{|l|}{ Smoking (\% of subgroup) } \\
\hline Current & 11.20 & 9.80 & 6.90 & 15.70 & 6.60 & 13.70 & 12.00 & 11.20 \\
\hline Former & 39.20 & 43.00 & 39.40 & 44.40 & 42.80 & 46.30 & 39.90 & 44.30 \\
\hline $\begin{array}{l}\text { Heavy alcohol use (\% of } \\
\text { subgroup) }\end{array}$ & 17.40 & 23.70 & 23.00 & 15.60 & 18.50 & 12.10 & 18.90 & 21.70 \\
\hline $\begin{array}{l}\text { Two or more sinus infections } \\
\text { (\% of subgroup) }\end{array}$ & 44.50 & 29.80 & 20.00 & 33.20 & 39.40 & 35 & 42.00 & 37.60 \\
\hline $\begin{array}{l}\text { Nasal/facial fracture (\% of } \\
\text { subgroup) }\end{array}$ & 15.60 & 21.40 & 22.40 & 16.30 & 9.70 & 20.80 & 18.90 & 16.70 \\
\hline $\begin{array}{l}\text { Persistent cold/flu in past year } \\
\text { (\% of subgroup) }\end{array}$ & 7.60 & 4.70 & 3.00 & 4.70 & 8.40 & 6.20 & 7.00 & 10.50 \\
\hline $\begin{array}{l}\text { Caloric intake }>3000 \mathrm{kcal} / \text { day } \\
\text { (\% of subgroup) }\end{array}$ & 27.60 & 32.10 & 66.40 & 70.90 & 70.90 & 66.00 & 73.00 & 69.00 \\
\hline
\end{tabular}

Table 1. Unweighted Cohort Characteristics, stratified by smell and taste dysfunction.

TD. Salty or bitter tastants were dissolved at known concentrations in aqueous solutions and then applied to the participants tongue-tip or whole mouth, in a standardized fashion ${ }^{(41)}$. Both tongue tip and whole mouth testing was done to assess local 
Table 2. Univariate analyses of smell and taste dysfunction versus obesity.

\begin{tabular}{|lcccc|}
\hline Obesity & $\begin{array}{c}\text { Odds } \\
\text { Ratio }\end{array}$ & P value & \multicolumn{2}{c|}{$\begin{array}{c}95 \% \text { Confidence } \\
\text { Interval }\end{array}$} \\
\hline Anosmia + Hyposmia & 0.64 & $0.025^{*}$ & 0.44 & 0.94 \\
\hline Anosmia & 0.58 & 0.19 & 0.25 & 1.34 \\
\hline Hyposmia & 0.69 & 0.075 & 0.45 & 1.04 \\
\hline Normosmia & 1.56 & $0.025^{*}$ & 1.07 & 2.28 \\
\hline $1 \mathrm{mM}$ Quinine & 1.01 & 0.95 & 0.63 & 1.63 \\
\hline $1 \mathrm{mM} \mathrm{NaCl}$ & 0.85 & 0.69 & 0.36 & 2.00 \\
\hline $0.32 \mathrm{M} \mathrm{NaCl}$ & 0.64 & $0.023^{*}$ & 0.44 & 0.93 \\
\hline Tongue-tip Quinine & 0.93 & 0.72 & 0.63 & 1.38 \\
\hline Tongue-tip NaCl & 0.84 & 0.28 & 0.60 & 1.17 \\
\hline
\end{tabular}

${ }^{*} \mathrm{p}<0.05 ; \mathrm{NaCl}=$ sodium chloride; $\mathrm{M}=$ molar
Table 3. Univariate analyses of smell and taste dysfunction versus metabolic syndrome (MS).

\begin{tabular}{|lcccc|}
\hline Metabolic Syndrome & $\begin{array}{c}\text { Odds } \\
\text { Ratio }\end{array}$ & P value & \multicolumn{2}{c|}{$\begin{array}{c}95 \% \text { Confidence } \\
\text { Interval }\end{array}$} \\
\hline Anosmia + Hyposmia & 0.96 & 0.78 & 0.71 & 1.30 \\
\hline Anosmia & 0.59 & 0.11 & 0.30 & 1.15 \\
\hline Hyposmia & 1.14 & 0.49 & 0.78 & 1.66 \\
\hline Normosmia & 1.04 & 0.78 & 0.77 & 1.40 \\
\hline $1 \mathrm{mM}$ Quinine & 1.05 & 0.86 & 0.62 & 1.77 \\
\hline $1 \mathrm{mM} \mathrm{NaCl}$ & 0.80 & 0.60 & 0.32 & 1.97 \\
\hline $0.32 \mathrm{M} \mathrm{NaCl}$ & 0.78 & 0.28 & 0.49 & 1.24 \\
\hline Tongue-tip Quinine & 1.45 & $0.010^{*}$ & 1.11 & 1.90 \\
\hline Tongue-tip NaCl & 1.22 & 0.33 & 0.80 & 1.87 \\
\hline
\end{tabular}

* $\mathrm{p}<0.05 ; \mathrm{NaCl}=$ sodium chloride; $\mathrm{M}=$ molar taste as well as taste using the entire gustatory apparatus, which includes taste receptors on the anterior and posterior tongue, soft palate and pharynx, among other sites as well ${ }^{(42)}$. The tastants included whole mouth 1 molar (M) sodium chloride $(\mathrm{NaCl})$, whole mouth $0.32 \mathrm{M} \mathrm{NaCl}$, whole mouth $1 \mathrm{mM}$ quinine, tongue tip $1 \mathrm{M} \mathrm{NaCl}$, and tongue tip $1 \mathrm{mM}$ quinine. For tongue tip testing, participants then had to identify the tastant from 5 possible choices (salty, bitter, sour, some other taste, or no taste). For whole mouth testing, the participant was asked to provide a a tastant-specific intensity rating as well as identify the tastant from the same 5 choices ${ }^{(43)}$. The relationship of each test item with obesity or MS was investigated individually.

Obesity was evaluated by measurement of participants body mass index (BMI). Participant's height and weight were collected by trained health technicians. BMI was then calculated as weight, in kilograms, divided by height, in meters squared. Obesity was defined as a BMI $\geq 30 \mathrm{~kg} / \mathrm{m}^{2}(15,17)$.

Participants were categorized as having MS if the following conditions, based on published criteria, were met: blood pressure greater than or equal to $130 \mathrm{mmHg}$ systolic and $85 \mathrm{mmHg}$ diastolic, waist circumference $\geq 102 \mathrm{~cm}$ in men or $88 \mathrm{~cm}$ in women, a fasting blood glucose level $\geq 100 \mathrm{mg} / \mathrm{dL}$, a serum triglyceride level $\geq 150 \mathrm{mg} / \mathrm{dL}$, and a serum high-density lipoprotein (HDL) level $<40 \mathrm{mg} / \mathrm{dL}$ in men or $50 \mathrm{mg} / \mathrm{dL}$ in women ${ }^{(15,16)}$. Despite the distinct criteria for obesity and MS, many participants met criteria for inclusion in both groups. They were analyzed as part of each group they met criteria for and included in both groups if applicable.

Similarly to BMI, blood pressure was measured by trained health technicians after participants were resting quietly in a seated position for 5 minutes. Triglycerides and HDL were measured using standard laboratory procedures on Roche Modular P and Roche Cobra 6000 chemistry analyzers. Fasting blood glucose was determined by the University of Missouri-Columbia me- thods and equipment. Refer to NHANES 2013-2014 Laboratory Method Files for comprehensive descriptions of the aforementioned procedures ${ }^{(37)}$.

The NHANES 2013-2014 dataset was interrogated for all participants age 60 or older with complete data in the smell, taste, BMI, and metabolic syndrome testing components. Covariates were also included: age, gender, race, education, annual household income, hypertension, cardiovascular disease, diabetes, stroke, smoking, heavy alcohol use (more than 4 drinks a day), sinus infection in the past year, a problem with a smell in the last year, ever having a facial injury or broken nose, persistent cold or flu in the last year, and caloric intake. These covariates are further described in Table 1. 95\% confidence intervals were used to estimate the population prevalence of SD, TD, obesity and MS. Then, logistic regression models were constructed to explore the associations between obesity and SD and TD as well as MS and SD and TD. STATA 14.2 software (www.stata.com, RRID:SCR_012763) was used to conduct all statistical analyses.

\section{Statistical analysis}

Initially, exploratory univariate logistic regressions were used to analyze the associations between obesity and SD, obesity and TD, MS and SD, and MS and TD. Then, these same associations were explored with multivariate models. Obesity and MS are associated with a variety of demographic and comorbid medical conditions; therefore, multivariate regressions were required to comprehensively explore these associations. In these multivariate models, we controlled for the aforementioned confounding variables. The outcome was presence of obesity or MS in each model. The predictors were SD or TD. Age was the only continuous covariate. All other covariates, shown in Table 1, were categorical. These models were built in stepwise backward elimination fashion until only statistically significant predictors were left in the model. The Homer-Lemeshow test was performed for 
Table 4. Multivariate analyses of $0.32 \mathrm{M}$ taste dysfunction versus obesity.

\begin{tabular}{|lcccc|}
$\begin{array}{l}\text { Metabolic } \\
\text { Syndrome }\end{array}$ & Odds Ratio & P value & \multicolumn{2}{c|}{$95 \%$ Confidence Interval } \\
\hline $0.32 \mathrm{M} \mathrm{NaCl}$ & 0.27 & $0.011^{*}$ & 0.11 & 0.66 \\
\hline Age & 0.94 & $<0.001^{*}$ & 0.91 & 0.98 \\
\hline $\begin{array}{l}\text { Hyperten- } \\
\text { sion }\end{array}$ & 0.51 & $0.021^{*}$ & 0.30 & 0.87 \\
\hline $\begin{array}{l}\text { Smoking } \\
\text { Excessive }\end{array}$ & 2.47 & $<0.001^{*}$ & 1.47 & 4.14 \\
\hline $\begin{array}{l}\text { Alcohol Use } \\
\text { Persistent }\end{array}$ & 0.55 & $<0.001^{*}$ & 0.39 & 0.79 \\
$\begin{array}{l}\text { cold/flu in } \\
\text { past year }\end{array}$ & 0.39 & $0.010^{*}$ & 0.21 & 0.75 \\
\hline
\end{tabular}

${ }^{*} \mathrm{p}<0.05 ; \mathrm{NaCl}=$ sodium chloride; $\mathrm{M}=$ molar

Table 5. Multivariate analyses of tongue-tip quinine taste dysfunction versus metabolic syndrome.

\begin{tabular}{|c|c|c|c|c|}
\hline $\begin{array}{l}\text { Metabolic } \\
\text { Syndrome }\end{array}$ & Odds Ratio & $P$ value & \multicolumn{2}{|c|}{$\mathbf{9 5} \%$ Confidence Interval } \\
\hline $\begin{array}{l}\text { Tongue-tip } \\
\text { Quinine }\end{array}$ & 1.48 & $0.010^{*}$ & 1.12 & 1.95 \\
\hline Diabetes & 0.59 & $<0.001^{*}$ & 0.47 & 0.73 \\
\hline
\end{tabular}

${ }^{*} \mathrm{p}<0.05 ; \mathrm{NaCl}=$ sodium chloride; $\mathrm{M}=$ molar

each multivariate model to ensure goodness of fit. All significant tests had a type I error rate of 0.05 or less.

\section{Results}

A total of 1,382 participants had complete obesity, MS, smell, and taste survey data. This corresponds to a weighted population size of 51 million. The demographics of these participants, as well as the prevalence of the various SDs and TDs, are described in Table 1. Combined TD had a prevalence of $24.92 \%$ (95\% Cl: 22.05-28.02). The prevalence of obesity in this population is $38.70 \%$ (95\% Cl: $36.13-41.27$ ). The prevalence of MS is $65.60 \%$ (95\% Cl: 57.60-70.31). Obesity and MS are related entities with definitions that allow for overlap between populations. $30.11 \%$ of participants with a full set of data had both obesity and MS, $35.49 \%$ MS only, $8.59 \%$ obesity only, and $25.81 \%$ met criteria for neither obesity, nor MS.

Anosmia + hyposmia was significantly associated with a decreased risk of obesity at the time of data collection in only univariate analysis $(\mathrm{OR}=0.64, \mathrm{P}=0.025, \mathrm{Cl}=0.44-0.94)$, see Table 2 . Normosmia was significantly associated with an increased risk of obesity at the time of data collection in univariate analysis alone $(\mathrm{OR}=1.56, \mathrm{P}=0.025, \mathrm{Cl}=1.07-2.28)$, as seen in Table 2. 0.32M $\mathrm{NaCl}$ TD is significantly associated with a decreased risk of obesity at time of data collection in univariate $(\mathrm{OR}=0.64, \mathrm{P}=0.023$, $\mathrm{Cl}=0.44-0.93)$, as well as multivariate $(\mathrm{OR}=0.27, \mathrm{P}=0.011, \mathrm{Cl}=$
Table 6. Summary of significant associations found between smell and taste dysfunction and obesity and metabolic syndrome.

\begin{tabular}{|c|c|c|c|}
\hline \multicolumn{4}{|l|}{ Obesity } \\
\hline & $\begin{array}{l}\text { Univariate } \\
\text { analysis }\end{array}$ & $\begin{array}{l}\text { Multivariate } \\
\text { analysis }\end{array}$ & Interpretation \\
\hline $\begin{array}{l}\text { Anosmia + } \\
\text { Hyposmia }\end{array}$ & $\begin{array}{l}\text { OR 0.64, } \\
P=0.025 \\
(95 \% \mathrm{Cl} 0.44- \\
0.94)\end{array}$ & - & $\begin{array}{l}\text { Neither nor- } \\
\text { mosmia nor SD } \\
\text { correlated with } \\
\text { obesity risk after } \\
\text { controlling for } \\
\text { covariates }\end{array}$ \\
\hline Normosmia & $\begin{array}{l}\text { OR 1.56, } \\
P=0.025 \\
(95 \% \mathrm{Cl} 1.07- \\
2.28)\end{array}$ & - & \\
\hline $\begin{array}{l}0.32 \mathrm{M} \mathrm{NaCl} \\
\text { TD }\end{array}$ & $\begin{array}{l}\text { OR 0.64, } \\
P=0.023 \\
(95 \% \mathrm{Cl} 0.44- \\
0.93)\end{array}$ & $\begin{array}{l}\text { OR 0.27, } \\
\mathrm{P}=0.011(95 \% \\
\mathrm{Cl} 0.11-0.66)\end{array}$ & $\begin{array}{l}\text { Salty TD was } \\
\text { associated with } \\
\text { decr risk of obe- } \\
\text { sity (covariates } \\
\text { controlled) }\end{array}$ \\
\hline \multicolumn{4}{|l|}{$\begin{array}{l}\text { Metabolic } \\
\text { Syndrome }\end{array}$} \\
\hline & $\begin{array}{l}\text { Univariate } \\
\text { analysis }\end{array}$ & $\begin{array}{l}\text { Multivariate } \\
\text { analysis }\end{array}$ & Interpretation \\
\hline $\begin{array}{l}\text { Tongue-tip } \\
\text { Quinine TD }\end{array}$ & $\begin{array}{l}\text { OR 1.45, } \\
P=0.010 \\
(95 \% \mathrm{Cl} 1.11- \\
1.90)\end{array}$ & $\begin{array}{l}\text { OR 1.448, } \\
P=0.010 \\
(95 \% \mathrm{Cl} 1.12- \\
1.95)\end{array}$ & $\begin{array}{l}\text { Bitter TD was } \\
\text { associated with } \\
\text { incr risk of MS } \\
\text { (covariates } \\
\text { controlled) }\end{array}$ \\
\hline
\end{tabular}

Significant $(P<0.05)$ results aggregated from tables $2-5 . S D=$ smell dysfunction; TD = taste dysfunction.

0.11-0.66) analyses (Table 2 and Table 4).

Tongue-tip quinine TD is the only taste variable significantly associated with $\mathrm{MS}$ in both univariate $(\mathrm{OR}=1.45, \mathrm{P}=0.010, \mathrm{Cl}=$ 1.11-1.90) and multivariate analyses $(\mathrm{OR}=1.48, \mathrm{P}=0.010, \mathrm{Cl}=$ 1.12-1.95), as shown in Table 3 and Table 5. No SD variable was significantly associated with MS.

Significant results and interpretations are summarized in Table 6.

\section{Discussion}

To the best of our knowledge, this study is the first to examine the association between quantitative smell or taste dysfunction and obesity or MS in adults age 60 or older using the NHANES nationally representative dataset. Our nationally representative estimate of obesity prevalence is $38.7 \%$ in older adults; literature estimates center around $40 \%{ }^{(15,17,19)}$. Our nationally representative estimate of MS prevalence in older adults is $65.6 \%$. This is nearly twice as high as the literature estimates of both the adult and older adult populations ${ }^{(15,28,31,43)}$. Based on the World Health Organization, Centers for Disease Control and Prevention, and the literature, prevalence of MS is about $30-40 \%$ of the adult population ${ }^{(15,28,43)}$. The reason for the higher prevalence in our study population is unclear, but it may be due to country-based 
differences, as other studies have occurred primarily in continental Europe. Additionally, the prevalence of MS will vary based on the definition used, as well as gender and race proportions in the study sample.

In this study, we found quantitative $\mathrm{NaCl}$ TD to be associated with a decreased risk of obesity and quantitative quinine TD to be associated with an increased risk of metabolic syndrome, after controlling for confounding factors. It is interesting to note that poor ability to taste salt, a common seasoning in many foods, decreases the risk of obesity. It is also interesting that poor ability to taste quinine, a bitter taste, increases the risk of metabolic syndrome. This could suggest that individuals with decreased capacity to taste certain flavors may be selecting certain foods that alter their risk of developing obesity or MS. The literature regarding this possible trend is contradictory. Simchen et al. found that individuals of 65 years old or more with a BMI $>27 \mathrm{~kg} / \mathrm{m}^{2}$ had a significantly poorer ability to detect sour tastes, an increased ability to detect salty, bitter, and sweet tastes ${ }^{(22)}$. Hardikar et al. had similar results, showing that obese individuals were more sensitive to salty and sweet flavors, and perceived them as more intense, compared to leaner controls ${ }^{(27)}$. However, Vignini et al. reported that increasing BMI was associated with a general decrease in detecting salt, sweet, sour and bitter tastes ${ }^{(26)}$. Sartor et al. showed that obese subjects perceived salty and sweet tastes as less intense ${ }^{(23)}$.

These studies were all limited by small sample sizes and specific study populations. Our results, that salty TD decreases the risk of obesity and bitter TD increases the risk of MS, seem to support the findings of Simchen et al. and Hardikar et al. Taken together, these findings support the hypothesis that capacity for detecting particular tastes may influence food selection and therefore the risk of developing metabolic diseases (e.g. obesity and MS). However, we are only able to measure associations in our analyses and further rigorous study is needed to identify if specific tastes are associated with risk of obesity or MS. This is especially true regarding MS, as only a paucity of literature investigating this topic currently exists. Additionally, these tastants are tested in isolation, and how they influence food choice cannot be determined from our results.

With respect to SD, our univariate analyses suggest that anosmia + hyposmia may decrease the risk of obesity, while individuals with normal smell capacity are at an increased risk of developing this disease. Given the known effect of smell on food consumption, it is possible that SD could lead to food preferences that are protective against metabolic disease. In fact, Rasmussen et al. found that individuals with diabetes and SD consumed fewer total calories per day compared to diabetics without SD ${ }^{(10)}$. However, our univariate SD results are not supported in our multivariate obesity models and therefore we can make no conclusions based on our results.

The current literature regarding the association between obesity and SD is contradictory. Richardson et al. found that quantitative SD was more prevalent in morbidly obese individuals compared to moderately-obese controls ${ }^{(24)}$. However, Simchen et al. showed that quantitative SD was less prevalent in obese individuals, compared to non-obese controls, if they were age 65 years or more ${ }^{(22)}$. Notably, both of these studies were limited by small sample sizes and non-representative patient populations. It is worth mentioning that our results stand in direct contrast to Liu et al., who used the 2013-14 NHANES dataset to show that neither obesity (categorical) nor BMI as a continuous variable was associated with quantitative SD or TD in adults 40 years or older ${ }^{(4)}$. However, these authors defined smell dysfunction as failing to identify 6 or more odors on the 8-item Pocket Smell test and defined taste dysfunction as failure to identify sodium or quinine using both the whole-mouth and tongue-tip solutions for each flavor ${ }^{(4)}$. It is possible that the stricter definitions of SD and TD used in Liu et al.'s investigation, in addition to the larger age range, were unable to capture the specific associations found in our study. However, since their sample size was larger, it is possible that their results are more robust than ours. Again, more investigations are needed to characterize the link between SD and TD and obesity and MS.

Our paper has several limitations. Firstly, we could only include confounders in our multivariate models that were captured in the NHANES dataset. For example, NHANES does not include a sweet item in its taste identification test. We were therefore unable to specifically evaluate if impaired ability to taste sweet flavors was associated with obesity or MS. We were also unable to control for cognitive dysfunction or neurodegenerative diseases, which can affect the ability to smell and taste ${ }^{(4,9,29)}$. Another limitation of our study is the lack of gold standard for diagnosing SD and TD. The methods used in NHANES, while quantitative, are concise and must be administered on a population level; therefore, they may not capture the same information as more detailed examinations. These tests also only occur on a single occasion, which may not accurately represent long-term function. Additionally, since the NHANES database is across-sectional survey at a single time-point, we cannot prove causality in our study, only associations.

\section{Conclusion}

Smell and taste dysfunction are relatively prevalent among older adults in the United States. Using a nationally representative dataset, we show that quantitative salty TD decreases the risk of obesity in adults age 60 or greater, while quantitative bitter TD increases the risk of metabolic syndrome in the same population. These findings suggest that TDs may be influencing food preferences, leading to altered risk of developing obesity or MS. Further studies are needed to characterize the associations between smell and taste dysfunction and obesity or MS. 


\section{Authorship contribution}

SSD: Data analysis and interpretation, manuscript preparation and revisions; JJQ: Data collection, data analysis and interpretation, manuscript preparation; SCP: Project conception, manuscript revisions; JLM: Principal Investigator, project conception and design, manuscript revisions.

\section{Acknowledgments}

None.

\section{Funding}

No sources of funding to declare.

\section{Ethics approval and consent to participate}

No approval or consent needed as only publicly available data was used.

\section{Consent for publication}

Not applicable.

\section{Availability of data and materials}

The datasets generated and/or analyzed during the current study are available in the National Health and Nutrition Examination Survey 2013-2014 repository, https://wwwn.cdc.gov/ nchs/nhanes/continuousnhanes/default.aspx?Begin Year=2013.

\section{Conflict of interest}

The authors declare that they have no competing interests.

\section{References}

1. Brämerson A, Nordin S, Bende M. Clinical experience with patients with olfactory complaints, and their quality of life. Acta Oto-Laryngologica. 2009;127(2):167-174.

2. Devanand DP, Lee S, Manly J, et al. Olfactory identification deficits and increased mortality in the community. Ann Neurol. 2015;78(3):401-411

3. Pence TS, Reiter ER, DiNardo LJ, Costanzo RM. Risk Factors for Hazardous Events in Olfactory-Impaired Patients. JAMA Otolaryngol Head Neck Surg. 2014;140(10):951-955.

4. Liu G, Zong G, Doty RL, Sun Q. Prevalence and risk factors of taste and smell impairment in a nationwide representative sample of the US population: a cross-sectional study. BMJ Open. 2016;6(11):e013246-e013246.

5. Schubert CR, Cruickshanks KJ, Fischer ME, et al. Olfactory impairment in an adult population: the Beaver Dam Offspring Study. Chem Senses. 2012;37(4):325-334.

6. Bhattacharyya N, Kepnes LJ. Contemporary assessment of the prevalence of smell and taste problems in adults. Laryngoscope. 2014;125(5):1102-1106.

7. Murphy C, Schubert CR, Cruickshanks KJ, Klein BEK, Klein R, Nondahl DM. Prevalence of Olfactory Impairment in Older Adults. JAMA. 2002;288(18):2307-2312.

8. Hoffman HJ, Ishii EK, Macturk RH. AgeRelated Changes in the Prevalence of Smell/Taste Problems among the United States Adult Population: Results of the 1994 Disability Supplement to the National Health Interview Survey (NHIS). Ann N Y Acad Sci. 1998;855(1):716-722

9. Boesveldt S, de Graaf K. The Differential Role of Smell and Taste For Eating Behavior. Perception. 2017;46(3-4):307-319.

10. Rasmussen VF, Vestergaard ET, Hejlesen O, Andersson CUN, Cichosz SL. Prevalence of taste and smell impairment in adults with diabetes: A cross-sectional analysis of data from the National Health and Nutrition Examination Survey (NHANES). Prim Care Diabetes. 2018 Oct;12(5):453-459.

11. Wasalathanthri S, Hettiarachchi P, Prathapan S. Sweet taste sensitivity in pre-diabetics, diabetics and normoglycemic controls: a comparative cross sectional study. BMC Endocr Disord. 2014;14(1):67.

12. Gondivkar SM, Indurkar A, Degwekar S, Bhowate R. Evaluation of gustatory function in patients with diabetes mellitus type 2 Oral Surg Oral Med Oral Pathol Oral Radiol Endod. 2009 Dec;108(6):876-80

13. Naka A, Riedl M, Luger A, Hummel T, Mueller CA. Clinical significance of smell and taste disorders in patients with diabetes mellitus. Eur Arch Otorhinolaryngol. 2010 Apr;267(4):547-50.

14. Riera CE, Tsaousidou E, Halloran J, et al. The Sense of Smell Impacts Metabolic Health and Obesity. Cell Metabolism. 2017;26(1):198-211.e5.

15. Engin A. The Definition and Prevalence of Obesity and Metabolic Syndrome. Adv Exp Med Biol. 2017;960:1-17.

16. Hwang $\mathrm{S}-\mathrm{H}$, Kang J-M, Seo J-H, Han $K-D$, Joo Y-H. Gender Difference in the Epidemiological Association between Metabolic Syndrome and Olfactory Dysfunction: The Korea National Health and Nutrition Examination Survey. PLoS One. 2016;11(2):e0148813-e0148813.

17. Engin A. Obesity-associated Breast Cancer: Analysis of risk factors. Adv Exp Med Biol. 2017;960:571-606.

18. Morelli N, Barello S, Mayan M, Graffigna G. Supporting family caregiver engagement in the care of old persons living in hard to reach communities: A scoping review. Health Soc Care Community. 2019;27(6):1363-1374

19. Flegal KM, Kruszon-Moran D, Carroll MD Fryar CD, Ogden CL. Trends in Obesity Among Adults in the United States, 2005 to
2014. JAMA. 2016;315(21):2284.

20. Jensen GL. Obesity and Functional Decline: Epidemiology and Geriatric Consequences. Clin Geriatr Med. 2005 Nov;21(4):677-87.

21. Vincent HK, Vincent KR, Lamb KM. Obesity and mobility disability in the older adult. Obes Rev. 2010;11(8):568-579.

22. Simchen U, Koebnick C, Hoyer S, Issanchou $\mathrm{S}$, Zunft $\mathrm{H}-\mathrm{J}$. Odour and taste sensitivity is associated with body weight and extent of misreporting of body weight. Eur J Clin Nutr. 2006 Jun;60(6):698-705.

23. Sartor F, Donaldson LF, Markland DA, Loveday H, Jackson MJ, Kubis H-P. Taste perception and implicit attitude toward sweet related to body mass index and soft drink supplementation. Appetite. 2011;57(1):237246.

24. Richardson BE, Vander Woude EA, Sudan R, Thompson JS, Leopold DA. Altered Olfactory Acuity in the Morbidly Obese. Obes Surg. 2004 Aug;14(7):967-9.

25. Patel ZM, DelGaudio JM, Wise SK. Higher Body Mass Index Is Associated with Subjective Olfactory Dysfunction. Behav Neurol. 2015;2015:675635-675635.

26. Vignini A, Borroni F, Sabbatinelli J, et al. General Decrease of Taste Sensitivity Is Related to Increase of BMI: A Simple Method to Monitor Eating Behavior. Dis Markers. 2019;2019:2978026-2978026.

27. Hardikar S, Höchenberger R, Villringer A, Ohla K. Higher sensitivity to sweet and salty taste in obese compared to lean individuals. Appetite. 2017;111:158-165.

28. Jacobson A, Green E, Haase L, Szajer J, Murphy C. Age-Related Changes in Gustatory, Homeostatic, Reward, and Memory Processing of Sweet Taste in the Metabolic Syndrome: An fMRI Study. Perception. 2017;46(3-4):283-306.

29. Alberti KGMM, Eckel RH, Grundy SM, et al. Harmonizing the Metabolic Syndrome. Circulation. 2009;120(16):1640-1645.

30. Huang Z, Huang S, Cong H, et al. Smell and 
Taste Dysfunction Is Associated with Higher Serum Total Cholesterol Concentrations in Chinese Adults. J Nutr. 2017;147(8):15461551.

31. Van Ancum JM, Jonkman NH, van Schoor NM, et al. Predictors of metabolic syndrome in community-dwelling older adults. Ginsberg SD, ed. PLoS ONE. 2018:13(10):e0206424.

32. Mottillo S, Filion KB, Genest J, et al. The Metabolic Syndrome and Cardiovascular Risk. J Am Coll Cardiol. 2010 Sep 28:56(14):1113-32.

33. Blazer DG, Hybels CF, Fillenbaum GG. Metabolic Syndrome Predicts Mobility Decline in a Community-Based Sample of Older Adults. J Am Geriatr Soc. 2006;54(3):502-506.

34. Penninx BWJH, Nicklas BJ, Newman AB, et al. Metabolic Syndrome and Physical Decline in Older Persons: Results from the Health, Aging and Body Composition Study. J Gerontol A Biol Sci Med Sci. 2009 Jan;64(1):96-102.

35. Carriere I, Pérès K, Ancelin ML, et al. Metabolic Syndrome and Disability: Findings From the Prospective ThreeCity Study. J Gerontol A Biol Sci Med Sci. 2013;69(1):79-86.

36. Roriz-Cruz M, Rosset I, Wada T, et al.
Stroke-Independent Association Between Metabolic Syndrome and Functional Dependence, Depression, and Low Quality of Life in Elderly CommunityDwelling Brazilian People. J Am Geriatr Soc 2007:55(3):374-382.

37. Johnson $\mathrm{CL}$, Dohrmann $\mathrm{SM}$, Burt $\mathrm{VL}$, Mohadjer LK. National Health and Nutrition Examination Survey: Sample design, 2011 2014. National Center for Health Statistics. Vital Health Stat 2. 2014 Mar;(162):1-33.

38. National Health and Nutrition Examination Survey. National Center for Health Statistics website. September 15, 2017. Accessed July 20, 2021. https://www.cdc.gov/nchs/ nhanes/about_nhanes.htm.

39. National Center for Health Statistics. Taste and Smell Examination Component Manual 2013. May 2013:1-90.

40. Rawal S, Hoffman HJ, Honda M, HuedoMedin TB, Duffy VB. The Taste and Smell Protocol in the 2011-2014 US National Health and Nutrition Examination Survey (NHANES): Test-Retest Reliability and Validity Testing. Chemosens Percept. 2015;8(3):138148.

41. 2013-2014 Data Documentation, Codebook, and Frequencies. Taste \& Smell. National Health and Examination Survey website. February 2016. Accessed July
20, 2021. https://wwwn.cdc.gov/Nchs/ Nhanes/2013-2014/CSX_H.htm

42. Higgins MJ, Hayes JE. Regional Variation of Bitter Taste and Aftertaste in Humans. Chem Senses. 2019:44(9):721-732.

43. Moore JX, Chaudhary N, Akinyemiju T. Metabolic Syndrome Prevalence by Race/ Ethnicity and Sex in the United States, National Health and Nutrition Examination Survey, 1988-2012. Prev Chronic Dis. 2017 Mar 16;14:E24.

Jose L. Mattos, MD MPH

University of Virginia School of

Medicine

1 Hospital Drive

2nd Fl., OMS, Room 2741

Charlottesville

VA 22903

USA

Tel: +1 (434) 924-5934

E-mail:jm6cb@virginia.edu 